\title{
PODER LOCAL Y CORRUPCIÓN JUDICIAL EN LA EXTREMADURA DEL SIGLO XVI: ALONSO DE MONROY (1583)*
}

\section{LOCAL POWER AND JUDICIAL CORRUPTION IN THE EXTREMADURA OF THE 16TH CENTURY: ALONSO DE MONROY (1583)}

\author{
Julián CLEMENTE RAMOS \\ Universidad de Extremadura
}

\begin{abstract}
Resumen
Alonso de Monroy, hijo de Francisco de Monroy y cuñado del conde de Medellín, protagoniza un intento de corrupción judicial con la finalidad de mantener una importante usurpación de tierras limítrofes al colmenar de su padre. Presiona o hace promesas a testigos y al escribano de Medellín. Asimismo, elige para su probanza a un escribano vinculado a su familia que no cumple las condiciones exigidas y que ha tenido una trayectoria llena de irregularidades. La justicia, sin embargo, muestra su capacidad para actuar ante esta situación e impedir que un personaje poderoso en el ámbito local, especialmente por la inacción del conde de Medellín, mediatice su actuación.
\end{abstract}

Palabras clave: Poder local, corrupción, justicia, Extremadura, Siglo XVI.

\begin{abstract}
Alonso de Monroy, son of Francisco de Monroy and brother-in-law of the count of Medellin, stars in an attempt of judicial corruption to a significant usurpation of land adjacent to the apiary of his father. He Tap or make any promises to witnesses and the notary of Medellín. Also, he choose for your evidence a notary attached to its family that does not meet the required conditions and has had a career full of irregularities. The justice, however, shows their ability to act in the face of this situation and prevent its mediatization by a powerful person with the inaction of the count of Medellin.

\footnotetext{
* La elaboración de este trabajo se ha beneficiado de fondos destinados a los grupos de investigación por la Junta de Extremadura para el periodo 2018-2021 (Grupo HUM023; Consejería de Economía e Infraestructuras; financiado con fondos FEDER).
} 
Key words: Local power, corruption, justice, Extremadura, sixteenth century.

\section{INTRODUCCIÓN}

La corrupción es un tema aparentemente recurrente en la sociedad medieval y moderna. Su estudio ha generado un interés creciente, algo que no es ajeno a la propia realidad española. Sin embargo, muchos aspectos que podrían considerarse como tales dentro de nuestros parámetros (venta de cargos, jurisdicciones particulares, etc.) constituyen realidades estructurales de la sociedad medieval y del antiguo régimen (Pérez, 1998: 127). Hay, sin embargo, actuaciones que se desarrollan claramente en contra de la legalidad en una sociedad que podemos considerar claramente de derecho desde la baja edad media atendiendo al número de letrados, a la importancia de la instancia judicial real y al sometimiento a las leyes, aunque los derechos personales no admiten la comparación con las modernas sociedades democráticas. En este sentido restringido sí podemos hablar de modo concreto de corrupción y prácticas corruptas que el propio entramado judicial intentó combatir y limitar, no siempre con éxito.

La propia estructura judicial fue campo de desarrollo de prácticas y actuaciones corruptas (Kagan, 1991: 61-2; Pérez, 1998: 125-6), sin que por ello dejase de jugar un papel decisivo en el mantenimiento del poder real y el equilibro social ${ }^{1}$, algo particularmente importante en las jurisdicciones señoriales ${ }^{2}$. Además de la corrupción desarrollada en el propio entramado judicial, la justicia no dejó de estar condicionada por el entorno social y político, y no sólo en el ámbito local, en manos de señores en muchos casos, sino también en la propia actuación de las Chancillerías y el Consejo Real. No estamos tanto ante casos de corrupción propiamente judicial como de intentos por parte de personas poderosas o de relativa relevancia de condicionar o pervertir los resultados de un proceso en el que estaban implicados.

\footnotetext{
${ }^{1}$ Kagan, 1991: 226-9 y sobre todo 111-2, donde analiza las sentencias de la Chancillería de Valladolid; para el ámbito local Lorenzana, 2003: 73. Quizás deberíamos recordar que esta contribución al equilibrio social, pese a todas sus imperfecciones y limitaciones, que tampoco desaparecen en nuestro tiempo, también se produce en la alta Edad Media antes del proceso de feudalización política. Bonnassie, Cataluña, pág. 84, nos indica que "aunque pueda parecer extraño, la justicia catalana del año 1000 no aparece realmente como una justicia de clase, en todo caso no traduce brutalmente la dominación del fuerte sobre el débil: fenómeno excepcional que tiene su explicación en las particularidades de la justicia social".

${ }^{2}$ Quintanilla Raso, 2003: 975-6; Bermejo Cabrero, 1975: 211; Guilarte, 1987: 213. La orden de Montesa ofrece un buen ejemplo de cómo Felipe II, incluso en Aragón, podía inmiscuirse en las jurisdicciones señoriales, socavando sus derechos (Hernández Ruano, 2008: 338-351).
} 
En un pleito sobre un colmenar de Francisco de Monroy en Medellín que se compone de cuatro cuadernillos, uno de ellos trata sobre las actuaciones irregulares de Alonso de Monroy en su intento de interferir en el proceso. Los datos sumnistrados sobre presiones realizadas a los testigos y al propio escribano nombrado por Medellín o sobre la elección de un escribano que no cumple las condiciones requeridas son precisos y detallados. Estamos ante un intento de mediatización de la justicia a partir de una posición de privilegio en el ámbito local. El pleito nos presenta una información de gran interés sobre las condiciones en que se desarrolla la actividad de la justicia real y de la capacidad de presión de los poderosos. La actuación judicial no puede entenderse al margen de las propias estructuras de poder, sin las cuales es posible que no lleguemos a entender sentencias sorprendentes que parecen chocar con las probanzas sin que pueda esbozarse una explicación coherente ${ }^{3}$.

Medellín y su tierra es un espacio jurisdiccional detentado por los Portocarrero desde la donación de Enrique IV en 1449 a Rodrigo Portocarrero, que poco después recibe el título condal (Clemente Ramos, 2007: 158-9). El poder condal, tras larga lucha contra la oligarquía y en particular con los Mejía, su linaje más cualificado, tuvo una consolidación paulatina. Hacia mediados del siglo XVI, está claramente asentado $^{4}$. Las actuaciones de la oligarquía tendrán éxito en la medida en que cuenten con la anuencia o permisividad condal. Todo el proceso que vamos a estudiar no puede entenderse, por tanto, al margen de las relaciones entre la familia implicada y los condes de Medellín. Pese a los intentos de tutelarlo y anularlo, el concejo sigue teniendo un rol no desdeñable aunque múltiples condicionantes limiten su autonomía. El tema que abordamos se asienta en el diálogo, complejo y no exento de contradicciones, aunque nunca pongan en peligro el sistema, entre los poderes locales, y su capacidad de condicionar la justicia, y el poder real.

\section{OLIGARQUÍA Y PODER CONDAL: FRANCISCO Y ALONSO DE MONROY}

El intento de interferencia sobre la acción judicial la desarrolla de modo prácticamente exclusivo Alonso de Monroy, hijo y heredero de Francisco de Monroy, propietario del colmenar objeto de disputa. ¿Quiénes son estos personajes? Alonso y Francisco de Monroy son nieto y bisnieto de Alonso Fernández Portocarrero, hermano de

\footnotetext{
${ }^{3}$ Es sorprendente, por ejemplo, el resultado de algunos pleitos a favor de la oligarquía local de Medellín, que en su mayor parte o la totalidad apoyó la causa de Isabel I frente a su sobrina Juana de Castilla (conocida impropiamente como la Beltraneja), tras claros procesos de apropiación de términos: cf. Clemente Ramos, 2019, págs. 146. Se trata de algo que requiere un estudio detenido.

${ }^{4}$ Es un tema que no se ha estudiado. Se ha tocado marginalmente en Clemente Ramos, 2019: 146-9 .
} 
Rodrigo Portocarrero (+ 1462), primer conde de Medellín (a. 1456), que recibió como ya hemos señalado la jurisdicción de esta villa de Enrique IV. Si bien, ambas líneas tienen un entendimiento total hasta la primera década del siglo XVI, desde entonces la línea segundona se distancia del conde Juan Portocarrero y empieza a actuar como una familia más de la oligarquía, entablando alianzas contra la autoridad jurisdiccional.

Alonso Fernández Portocarrero se casó sucesivamente con Inés Mejía, hija de Pedro Mejía, el más cualificado miembro de la oligarquía medellinense, que murió en su primer parto, y muy poco después, en 1451, con María de Sotomayor, hija de Alfón de Monroy y Juana de Sotomayor, con lo que entroncaba con las familias señoriales de Monroy y Belalcázar ${ }^{5}$. Esos enlaces fueron financiados por su hermano Rodrigo Portocarrero, futuro conde de Medellín, que le entregó entre otros bienes la dehesa de Martín Sancho, de la que se había apropiado ${ }^{6}$. El concejo de Medellín conseguirá la reversión de esta propiedad a principios del siglo XVI, por lo que Juan Portocarrero, $2^{\circ}$ conde de Medellín, entregará a la familia, constituida por María de Sotomayor y sus hijos Rodrigo Portocarrero, Alonso de Monroy y Elvira ${ }^{7}$, para sanear su anterior donación, "los ofiçios de alguaziladgo e escrivania de la dicha mi villa de Medellín e su tierra... para syenpre jamas". Hasta este momento, los hijos de Alonso Fernández Portocarrero, que desarrollan también una pronta vinculación con la orden de Santiago ${ }^{9}$, aparecen estrechamente vinculados a la familia condal ${ }^{10}$.

Esta última donación abre un periodo de enfrentamiento entre el conde de Medellín, Juan Portocarrero, con una clara política de control completo de la jurisdicción, y sus primos Rodrigo Portocarrero y Alonso de Monroy. Desde mayo de 1504, meses después de que éste se alineara con el conde en su intento de controlar el concejo local, el conde va a intentar apropiarse de la escribanía. Al margen de su rentabilidad económica, más de treinta mil maravedís anuales ${ }^{11}$, se añadía el interés condal en controlar todos los resortes de poder de la tierra/condado de Medellín. En

\footnotetext{
${ }^{5}$ AChG (=A. Ch. Granada), leg. 2072, nº 6, fols. 5v-6r. Franco Silva y del Pino, 1987: 156-7; Cabrera Muñoz, 1977: 177

${ }^{6}$ AChG, leg. 2072, $\mathrm{n}^{\circ}$ 6, fol. 1r; Clemente, 2006: 496-7.

${ }^{7}$ Alonso Fernández Portocarrero murió hacia 1490 (AChG, leg. 577, nº 24, fol. 10r)

${ }^{8}$ A. G. Simancas, Consejo Real, Leg. 658, exp. 19, fol. 3r.

9 "comendador que fue de las encomiendas del Oliva e Palomas" (AChG, c. 5390, n 2, fol. 31r); Gerbet, 1979: 284.

${ }^{10}$ En octubre de 1503, tras los intentos del conde de imponer sus candidatos en la elección concejil, Alonso de Monroy "siendo alguasyl de la dicha villa echo mano al espada e quiso matar un cavallero que se llamava Fernan Carrillo e el dicho conde le trae consygo sy que sobrello aya fecho castigo ni execucion alguna" (A. G. Simancas, R. G. Sello, 1503-octubre, $\sin n^{\circ}$ )

${ }^{11}$ Según Rodrigo Portocarrero y Alonso de Monroy, la escribanía podía valer “a justa e comunal estimaçion dende ocho dias del mes de mayo de mill e quinientos e quatro años hasta el postrero dia del mes de diciembre del dicho años de mill e quinientos e quatro años veynte mill mrs." (AChG, c. 5390, $\mathrm{n}^{\circ} 2$, fol. 30v).
} 
1506, los dos hermanos piden el seguro real junto a miembros cualificados de la oligarquía local, entre los que figura Juan Núñez de Prado, hijo de Pedro Mejía y líder de la oposición al conde ${ }^{12}$. En 1507, Alonso de Monroy da un poder con éste mismo personaje, de tanta importancia en el ámbito local ${ }^{13} \mathrm{y}$ el conde hizo derribar la casa de los dos hermanos ${ }^{14}$. En 1508, Rodrigo Portocarrero, ahora como comendador, y Alonso de Monroy siguen apareciendo en la "amistad de Juan Nuñez de Prado" ${ }^{15}$. El comendador Rodrigo Portocarrero debió morir en 1510 ó poco antes ${ }^{16}$.

Nuestra información es menos constante desde 1510. En 1520, Alonso de Monroy aparece entre los querellantes contra el conde por diversos agravios ${ }^{17}$. Según el propio conde, los pleitos de éste contra él son de "de mas de treynta e de quarenta quentos de ynterese" ${ }^{" 18}$. Este mismo año, Alonso de Monroy y Juan Núñez de Prado, junto a otros miembros de la oligarquía, aparecen como aliados de Rodrigo Portocarrero frente a su padre el conde Juan Portocarrero, del que era heredero ${ }^{19}$.

En 1521, el conde Juan Portocarrero llega a un acuerdo con Alonso de Monroy, "su primo". En compensación por el alguacilazgo de Medellín, le entrega cincuenta maravedís de juro en las tercias de Écija ${ }^{20}$. El conde realiza una concesión económica y recupera una atribución jurisdiccional. Los años siguientes debieron ser también conflictivos. En 1524, el conde, en lo que parece una ratificación del acuerdo anterior, cede "la novena parte de las terçias que el dicho señor conde tiene en la çibdad de Eçija, cresçiente e menguante, estando como agora estan las dichas terçias arrendadas e numeradas en quatroçientos e çinquenta mill maravedis de que viene por rata de la dicha novena parte çinquenta mill maravedis" en compensación por el alguacilazgo y "para [un] esclavo que le fue muerto al dicho Alonso de Monroy e çiertos puercos, cavallos e otras qualerquier cosas que de su casa dezia averle faltado e la avian sydo tomadas". Detrás de este acuerdo hay un evidente interés en que se produzca un cambio en las relaciones entre ambos, pues se precisa "que el dicho Alonso de Monroy tenga al dicho señor conde por señor e el dicho señor conde al dicho Alonso de Monroy por deudo e amigo" 21 .

${ }^{12}$ A. G. Simancas, R. G. Sello, 1506-octubre, s. f.

${ }^{13}$ A. G. Simancas, Camara de Castilla, Pueblos, leg. 11, $\mathrm{n}^{\circ} 382$.

${ }^{14}$ A. G. Simancas, R. G. Sello, 1507-jul-ag., s.n., fol. 1v

${ }^{15}$ A. G. Simancas, Camara de Castilla, Pueblos, 11/364, fol. 2v.

${ }^{16}$ En una provisión real de noviembre de 1510 se alude a "los herederos de Rodrigo Portocarrero" y Alonso de Monroy aparece representando a sus sobrinos, hijos de su hermano, en agosto de 1508 (AChG, c. 5398, ${ }^{\circ}$ 2, fol. 3r, y A. G. Simancas, Consejo Real, Leg. 73, exp. 8, fol. 36v)

${ }^{17}$ A. G. Simancas, Patronato Real, leg. 6, n ${ }^{\circ} 12$, fols. 270r-v.

${ }_{18}$ A. G. Simancas, Patronato Real, leg. 6, $\mathrm{n}^{\circ} 12$, fol. 252 r.

${ }^{19}$ Se puede seguir en A. G. Simancas, Patronato Real, leg. 6, no 12.

${ }^{20}$ A. D. Medinaceli, Medellín, leg. 3, $\mathrm{n}^{\circ} 21$.

${ }^{21} \mathrm{AChG}$, leg. 2072, $\mathrm{n}^{\mathrm{0}}$ 6, fols. 11v-12r. 
Alonso de Monroy ha tenido al menos dos hijos y cuatro hijas, todos ilegítimos como persona que siempre había permanecido soltera. En su testamento (a. 1527) instituye un mayorazgo a favor de Francisco de Monroy, su primogénito ${ }^{22}$, que tuvo con María de Sandoval, en el que se incluyen un noveno de las tercias de Écija, 3/4 en las tercia de Andújar, unas aceñas, el colmenar que sería objeto del pleito y unas casas situadas junto a la puerta del Guadamez, en Medellín. Igualmente, dota o entrega importantes cantidades económicas a sus hijas ${ }^{23}$. Algunos testigos le presentan como "cavallero prinçipal" con "muchos bienes e hazienda e yerva". En los últimos años de su vida aparece como "muy debdo del conde de Medellin". En su testamento alude a "el conde, mi señor" ${ }^{24}$. Se estima que su hijo Francisco de Monroy, principal beneficiario de su testamento, tenía doscientos mil maravedís de renta anual ${ }^{25}$, lo que le situaba en una buena posición económica dentro de la oligarquía local aunque lejos de sus miembros más cualificados ${ }^{26}$.

Francisco de Monroy debió nacer en 1515, pues en 1529, contaba con 14 años. Pese al acuerdo de 1521-4, las buenas relaciones entre su padre y el conde de Medellín duraron poco. En 1536, está pleiteando con el conde Juan Portocarrero sobre las tercias de Écija, por las que recibirá posteriormente compensaciones ${ }^{27}$. En 1539, lo hace junto a otros miembros de la oligarquía local por los "desafueros" que realiza el conde (apropiación de espacios comunales y derechos vecinales) ${ }^{28}$. El enfrentamiento entre Francisco de Monroy, y otros miembros de la oligarquía local, y el conde se mantuvo en los años siguientes ${ }^{29}$. Sabemos que algunos de ellos, entre ellos el mismo Francisco de Monroy, estuvieron presos en Medellín ${ }^{30}$. Este enfrentamiento constante llevó a miembros cualificados de este colectivo a abandonar la jurisdicción. Francisco de Monroy se asentó en Zalamea, donde le encontramos residiendo cuatro décadas después ${ }^{31}$.

No conocemos las relaciones entre Francisco de Monroy y la autoridad jurisdiccional de Medellín entre 1543 y 1583. La información suministrada en el pleito sobre

${ }^{22}$ AChG, legajo 2072, n ${ }^{\circ}$ 6, fols. 22v-26r.

${ }^{23} \mathrm{AChG}$, legajo 2072, $\mathrm{n}^{\circ}$ 6, fols. 25v-27r

${ }^{24}$ AChG, 3-504-7, leg. actual 483, fol. 27v; igualmente, 29v.

${ }^{25}$ AChG, 3-504-7, leg. actual 483, fol. 23v.

${ }^{26}$ Hemos estimado hacia 1500 una renta anual para Juan Núñez de Prado que podría alcanzar los quinientos mil maravedís (Clemente Ramos, 2014: 819).

${ }^{27}$ A. D. Medinaceli, Medellín, leg. 1, $\mathrm{n}^{\circ} 11-2$, y leg. $4, \mathrm{n}^{\circ} 23$; AChG, c. $1174, \mathrm{n}^{\circ} 4$, fol. $6 \mathrm{r}$.

${ }^{28}$ A. G. Simancas, Consejo Real, Leg. 230, exp. 4, fols. 9r-11v.

${ }^{29}$ A. G. Simancas, Consejo Real, Leg. 230, exp. 2-1, fol. 94v.

${ }^{30}$ A. G. Simancas, Consejo Real, Leg. 230, exp. 3, fol. 26r.

${ }^{31}$ A. G. Simancas, Consejo Real, Leg. 230, exp. 2-1, fol. 124r y 230, esp. 2 bis, fol. 79v; la explicación condal, aludiendo a otras razones para el abandono de Medellín por Francisco de Monroy, no es creíble: A. G. Simancas, Consejo Real, Leg. 230, exp. 3, fol. 31v. 
el colmenar nos hacen pensar que la distancia las ha mejorado sensiblemente. En la probanza de Medellín, se presenta a Francisco y a su hijo y heredero Alonso de Monroy, el personaje que intenta interferir en el pleito sobre el colmenar de la familia, como "caballeros de los mas ricos e prinçipales desta tierra, que tienen dos cuentos de renta" y "deudos muy cercanos del conde de Medellin". No parece que esta estrecha vinculación entre esta familia y los condes de Medellín sea una mera apreciación. Alonso de Monroy se casó con una hermana del conde, de la que desconocemos su identidad concreta ${ }^{32}$. Debemos considerar, en el momento en que se desarrolla el pleito sobre el colmenar, que la familia propietaria tiene una sólida posición económica y una estrecha vinculación con la autoridad jurisdiccional de Medellín, dentro de la cual se asienta el aludido colmenar. Es llamativo que a los intentos de apropiación de esta familia sólo se oponga el concejo pero no los condes de Medellín. La familia une poder económico y social en el ámbito comarcal de la mano de su proximidad con el conde, aspecto fundamental para explicar los hechos que a continuación analizaremos y que suponen un desafio en toda regla a la normal aplicación de la justicia real.

\section{ANDRÉS GUTIÉRREZ, UN ESCRIBANO INADECUADO}

El intento de corrupción de la justicia de Alonso de Monroy tiene dos claros soportes: Andrés Gutiérrez y la presión sobre la parte contraria. Andrés Gutiérrez es la persona elegida por Alonso de Monroy para hacer su probanza. Medellín se opone a esta elección porque no cumplía con la condición exigida, ser escribano público en lugar realengo ${ }^{33}$. Todo nos hace pensar que ni era persona recomendable ni podía exhibir imparcialidad alguna. Podemos trazar su devenir en líneas generales desde 1581. Andrés Gutiérrez había sido escribano efectivamente en Villanueva de la Serena, perteneciente al maestrazgo alcantarino, hasta este año y durante un tiempo que no podemos precisar ${ }^{34}$. No sabemos nada sobre cómo llegó a ocupar esta responsabilidad aparentemente tan alejada de sus capacidades. Hacia agosto o septiembre de 1581, huyó de Villanueva y se refugió en Valdetorres, aldea de Medellín muy

${ }^{32}$ AChG, c. 14443, no 11, cuad. 1, fols. 64r-66v. La Fundación Medinaceli recoge el matrimonio de Alonso de Monroy con María Portocarrero, hija de Juan Portocarrero, $3^{\text {er }}$ conde de Medellín, y hermana de Rodrigo Jerónimo, $4^{\circ}$ conde de Medellín, sin precisar su base documental (http://www.fundacionmedinaceli.org/casaducal/fichaindividuo.aspx?id=3115)

${ }^{33}$ A lo largo del siglo XVI va siendo menos frecuente que un receptor real recoja las declaraciones de los testigos, lo que abre paso a situaciones como la que vemos en que sólo se exige que lo haga un escribano de lugar realengo a elegir por los interesados, condición que incumple también Andres Gutiérrez, no así el elegido por Medellín, escribano en la tierra de Trujillo (Roldán Verdejo, 1989: 278-181).

${ }^{34} \mathrm{AChG}$, c. $14443, \mathrm{n}^{\mathrm{0}} 11$, cuad. 3, fol. $78 \mathrm{r}$ : "avia sido escrivano atras dos años del dicho tiempo" [c. ...-1581] 
próxima, donde vivió hasta enero de 1583 . Un juez de escribanos "le queria castigar por cosas que avia fecho malsonantes de su ofiçio" 35 . La información concreta sobre las irregularidades cometidas son imprecisas. Juan Gallego nos dice que la actuación del juez de escribanos se debía a que no tenía "sus papeles e registros bien aderesados". Juan Barrero habla de "una fianza [que] ay avia hecho" y Gonzalo Naharro, de "deudas"36. En cualquier caso, Andrés Gutiérrez no desarrolló adecuadamente su trabajo y tuvo actuaciones irregulares con la intención de obtener beneficios personales o para personas allegadas. Su huida, antes incluso de afrontar ninguna presencia ante el juez ${ }^{37}$, es un claro reconocimiento de culpabilidad. Hernán Mateos de Robres, criado del conde y pariente suyo en un grado que no sabe precisar, próximo por tanto al personaje, es tajante al valorarle: "le tiene por honbre muy extragado y de poca confianza e credito, y que le tiene ansimismo este testigo en mala reputacion y que hace muy mal su oficio descrivano" 38 .

En Valdetorres, el concejo no le quiso recibir como vecino, por lo que Andrés Gutiérrez solicitó y obtuvo de la justicia de Medellín un mandamiento para que se le aceptara. Aunque no sabemos las razones de esta decisión, adivinamos como un factor de cierta relevancia las relaciones de Francisco y Alonso de Monroy. En todo caso, su situación económica debía ser razonablemente buena en 1581, quizás debido a su anterior condición de escribano. Francisco de Cuéllar nos señala que en Valdetorres tenía "buena morada" y que araba, como un labrador más, con "dos mulas" en tierras colindantes a las suyas ${ }^{39}$.

No parece que Andrés Gutiérrez, además de no cumplir con los requerimientos impuestos por la justicia real, fuera una persona muy recomendable para hacer ninguna probanza. Sin duda, esta era la razón de su elección por Alonso de Monroy en sintonía con su padre Francisco de Monroy. Andrés Gutiérrez unía a todos los condicionantes ya señalados uno fundamental: su vinculación personal con su elector. El concejo de Medellín fundamentó su oposición en su condición de criado de Alonso de Monroy (en realidad, debemos entender que de su padre), algo de lo que "se jatava" 40 . Esta estricta dependencia entre escribano y pleiteante la avala Juan Díaz de Valera, el escribano elegido por Medellín, que también sufrirá junto a diversos testigos presiones para que no realice ninguna actuación. Este testigo vio cómo

\footnotetext{
${ }^{35}$ AChG, c. 14443, no 11, cuad. 3, fol. 63r

${ }^{36}$ AChG, c. 14443, no 11, cuad. 3, fols. 75v, 69r y 72r respectivamente.

37 "vido este testigo quel dicho Andres Gutierrez se ausento de la dicha villa de Villanueva e no quiso guardar al dicho juez e se vino al lugar de Valdetorres" (AChG, c. 14443, n 11, cuad. 3, fol. 78 r-v).

${ }^{38}$ AChG, c. 14443, no 11, cuad. 3, fol. 83r.

${ }^{39} \mathrm{AChG}$, c. $14443, \mathrm{n}^{\circ} 11$, cuad. 3, fol. $60 \mathrm{v}$.

${ }^{40}$ AChG, c. $14443, n^{\circ} 11$, cuad. 3, fol. 12.
} 
Andrés Gutiérrez compartía mesón con "los criados y cavalgaduras del dicho don Alonso de Monroy", con los que le vio "algunas vezes comer e bever". A Juan Díaz de Valera, en su condición de escribano, le parecieron graves las "sospechas" que esta actuación podía ocasionar aunque el interesado señalara que pagaba de sus propios recursos los gastos, algo que ningún otro testigo avala. En todo caso, le prometió, entendiendo que su actuación no era muy recomendable, "no comer mas con los criados del dicho con Alonso"41. Otros testigos ratifican esta versión ${ }^{42}$. Diego Alonso Carrasco, regidor de Medellín, nos ofrece dos informaciones adicionales de interés. Al parecer, vio cómo Andrés Gutiérrez tenía un trato muy próximo, "de vos", es decir, equivalente al tuteo actual, con Alonso de Monroy. Además, señala cómo el mismo Andrés Gutiérrez le indicó cómo él y otros hermanos suyos "heran criados viejos e hazedor de la casa del dicho don Alonso" ${ }^{" 43}$.

Las razones de la elección de Andrés Gutiérrez para hacer la probanza de Francisco de Monroy y de su hijo Alonso son claras. Andrés Gutiérrez era una persona manejable cuya actuación parcial sólo podía beneficiar a las personas a las que estaba desde largo tiempo vinculado. No parece que sus escrúpulos le impidieran salirse de los límites marcados por la ley, que intentaban garantizar la neutralidad e independencia de los testigos. El concejo de Medellín le requirió inmediatamente para que no hiciera la probanza por no cumplir las condiciones exigidas, lo cual no surtió efecto alguno ${ }^{44}$.

La probanza realizada por Andrés Gutiérrez, que no se ha conservado, debió estar llena de irregularidades. Sólo tenemos una información indirecta a partir de algunos testigos que recogen el parecer de Juan Díaz de Valera. Según Diego Alonso Carrasco, regidor de Medellín, que acompañó a este escribano, Andrés Gutiérrez hacía su probanza "muy bellacamente" y no sólo intentaba que los testigos declararan a favor de Alonso de Monroy sino que igualmente, si era necesario, cambiaba sus declaraciones ("aunque los testigos no lo dezian lo asentava") ${ }^{45}$. Todo parece

${ }^{41}$ AChG, c. 14443, $\mathrm{n}^{\circ} 11$, cuad. 3, fol. 36v.

${ }^{42}$ AChG, c. 14443, n⿳ 11, cuad. 3, fols. 52v-53r: Juan Rodríguez del Pozo señala que Andrés Gutiérrez "comia e bevia en la posada del dicho don Alonso y posava en ella y andava con el dicho don Alonso e con sus criados e jugava con ellos que al paresçer deste testigo paresçia el dicho Andres Gutierrez el c(r)iado del dicho don Alonso de Montoy por el trato que en su casa y posada tenia"

${ }^{43}$ AChG, c. $14443, \mathrm{n}^{\circ} 11$, cuad. 3 , fol. 43r.

${ }^{44}$ AChG, c. 14443, $\mathrm{n}^{\mathrm{o}}$ 11, cuad. 3, fol. 48r: "ante este testigo [Juan Vaquero, regidor], como escrivano que a la sazon hera quando se hizieron las dichas provanzas en el lugar de Almoharin, por parte de la villa de Medellin le fueron hechos çiertos requerimientos a el dicho Andres Gutierres y este testigo los escrivio en que le requirian que pues no hera escrivano publico de ningun pueblo ni lugar realengo de Su Magestad como lo mandava la real provisión reçetoria que no hizierese ninguna provanza pues no podia"

${ }^{45} \mathrm{AChG}$, c. $14443, \mathrm{n}^{\circ} 11$, cuad. 3 , fols. $38 \mathrm{v}-39 \mathrm{r}$. 
indicar que la probanza de Alonso de Monroy se hizo con escasa rigurosidad y con el único interés de obtener declaraciones reales o supuestas que avalaran la versión de Francisco y Alonso de Monroy.

\section{LA PRESIÓN SOBRE LOS TESTIGOS Y EL ESCRIBANO DE MEDE- LLÍN}

Junto a la elección de escribano, hay una doble línea de presión y/o captación sobre el escribano y los testigos. Una pregunta del interrogatorio se centra en el escribano Juan Díaz de Valera, que debía realizar la probanza de Medellín. Entre los testigos está el propio interesado, lo que nos permite disponer de una información de primera mano ${ }^{46}$. Su declaración se centra en las presiones de Alonso de Monroy para que niegue el intento de cohecho realizado el año anterior. Juan Díaz de Valera era escribano en Escurial, tierra de Trujillo, lugar próximo a Medellín. Había obtenido el cargo del monasterio de Santa María de Guadalupe, que detentaba las escribanías de esta jurisdicción. El 31 de marzo de 1583, le hizo llamar Alonso de Monroy que como indica "desde ayer lestava aguardando para hablarle". La razón de este interés es la petición que había realizado el procurador de Medellín en la Chancillería de Granada, estando ya concluso el proceso sobre el colmenar, sobre el supuesto cohecho que dicho personaje había intentado. Según la declaración de Juan Díaz de Valera, Alonso de Monroy hizo una amenaza velada pero no por ello menos clara, ofreciéndoles también supuestos beneficios. Ante cualquier receptor de la Chancillería, le aconseja que en su declaración "mirase como lo dezia porque este testigo hera cristiano y le tenia por honbre que no le haria agravio". Le amenaza con quitarle la escribanía al tener muy buenas relaciones con el monasterio de Guadalupe así como "mejorarle el oficio descrivano" si actuaba en la línea que le pedía. Igualmente le amenazó con represalias ("quando por aqui no fuese le obligaria a el a que por tercera persona se desagraviase de qualquier perjuizio que por la declaraçion deste testigo le viniese como amenzandole a este testigo"). Juan Díaz de Valera se mantuvo fiel a su obligación de "declarar verdad". Esa aparente serenidad no impidió que tuviera miedo tanto de la actuación de los monjes de Guadalupe, que posiblemente no creía probable, como de las posibles represalias de Alonso de Monroy y que intentase evitar la declaración, algo difícil dado que una parte sustantiva de la probanza se centraba en él ("este testigo quedo amedrantado e con pesadunbre porque si dezia su dicho no le quitasen el oficio descrivano la casa de Guadalupe por el dicho don Alonso y le

\footnotetext{
${ }^{46}$ AChG, c. 14443 , no 11, cuad. 3, fols. 33r-34r.
} 
viniese otro algun daño a su persona, y a procurado no declarar este su dicho hasta que por mi el dicho escrivano reçetor fue apremiado a que lo declarase" $)^{47}$. Juan Díaz de Valera, llamado por el receptor, declaró los hechos con precisión, algo que no hubiera deseado. Posiblemente no tenía otra posibilidad ante la existencia de otros testigos y ante la opción de quedar claramente en evidencia. La maquinaria judicial ha actuado sin sujetarse a ninguna presión y ha realizado su cometido, algo que debemos apreciar.

Alonso de Monroy quería que Juan Díaz de Valera negara el intento de cohecho que sufrió como escribano encargado de la probanza de Medellín en 1582. Diego Alonso Carrasco, regidor de Medellín y testigo directo, nos da una información precisa sobre la actuación de ambos. Juan Díaz de Valera, yendo a la aldea próxima de Miajadas, recibió una carta antes de entrar en el pueblo que le entregó un criado del cura de Escurial en la que se le decía, entre otras cosas que este testigo no recuerda, "que se bolviese a el Escurial y no fuese a hazer la provanza que vaya a hazer con este testigo porque don Alonso de Monroy se lo avia encomendado a el dicho cura y que mas le valia hazer la voluntad de don Alonso de Monroy, que hera un cavallero rico e que le pagaria bien que no hazer por un conçejo que no sabe agradeser nada" 48 . La petición fue infructuosa, quizás porque iba en compañía de un regidor de Medellín. Después de hacer su trabajo se desplazaron a Almoharín, donde un criado de Alonso de Monroy, Pedro de Saavedra el Mozo, le entregó otra carta en que le pedía "que le hiziese plazer de venirse luego a la villa de Medellin con el portador e que le traxese la ynformaçion que la villa andava haziendo para que la quería ver e hazer ynterrogatorio por ella para aprovar al contrario della, y que le dava su palabra que haria su provanza e que se lo pagaria muy bien, porque hera honbre quel que hazia por el se lo sabia muy bien pagar e agradeser". Alonso de Monroy amenazó, además, a Juan Díaz de Valera con darle "un alcabuzaso" si no hacía lo que le pedía. Igualmente, amenazó a un criado del regidor Diego Alonso con cortarle "las orejas y hazelle dar cien palos". Todas estas amenazas infundieron un profundo temor en el escribano "que no sabia que se hazer" 49 . Alonso de Torres, zapatero de Almoharín, que acogió a Juan Díaz de Valera en su casa mientras hizo la probanza en este lugar, sostiene, en la misma línea que Diego Alonso, que el escribano no aceptó el "cohecho" que se le propuso pero andaba muy atemorizado y "de noche no osava salir de

${ }^{47}$ Se documentan situaciones en que el poder de los implicados y la utilización de amenazas y/o sobornos generan declaraciones falsas o no ajustadas a la verdad. El ámbito local debió ser más proclive a actuaciones de este tipo (Gómez González, 2017: 327-8; Castellano, 1987: 257).

${ }^{48} \mathrm{AChG}$, c. 14443 , n ${ }^{\circ} 11$, cuad. 3, fol. 40r-v

${ }^{49} \mathrm{AChG}, \mathrm{c} .14443, \mathrm{n}^{\mathrm{o}} 11$, cuad. 3, fols. 40r-41r. 
la posada y casa deste testigo antes que [...] le rogava a este testigo se fuese con el”,50. Otros testigos confirman igualmente su profundo temor ${ }^{51}$.

No hay lugar a dudas de que hubo un intento evidente de interferir en la actuación de Juan Díaz de Valera, escribano de Medellín, mediante promesas de recompensas o amenazas, las cuales tras su negativa en ningún caso llegaron a materializarse, aunque le infundieran un profundo temor. Para ello Alonso de Monroy contó con significados miembros en el ámbito rural, como el cura de Escurial, con el que debía tener vínculos amistosos, todo lo cual debió redundar en hacer más creíbles las amenazas. Frente a esta situación y otras parecidas, la justicia real debía producir el suficiente respeto como para que las actuaciones no llegaran a la violencia física.

Las actuaciones de Alonso de Monroy y de su escribano Andrés Gutiérrez también se realizan sobre los testigos, eligiendo personas próximas o intentado que declarasen en función de sus intereses. No debemos olvidar que un testigo del que se demostrase su parcialidad no era apto para participar en una probanza. La información sobre este grupo es menos precisa aunque no de menor interés. Alonso de Torres, al que ya hemos aludido, nos indica cómo Andrés Gutiérrez "los metia [a sus testigos] en su posada y en la dicha su posada estava hablando con ellos en secreto, que al parescer deste testigo hera ynduzirlos a que dixesen sus dichos en su favor conforme el queria". Afirma, igualmente, que Alonso de Monroy "les dava dineros y les prometia otras cosas porque dixesen en su favor". Esta información gana credibilidad cuando descendemos a datos más concretos. García Hernández se negó a decir cosas que desconocía ("no, no, señor, yo no se nada de eso") y finalmente no participó como testigo ${ }^{52}$. Juan Vaquero, escribano y regidor de Montánchez, sostiene que Salvador Márquez vino de Valdemorales "a dezir su dicho en favor del dicho don Alonso". Alonso de Monroy habló con él, no sabemos si en la reunión ya señalada, y se empeñó en compensarle por el viaje, sin que sepamos si finalmente lo hizo. Entre ambos parece haber una cierta vinculación, puesto que este testigo vino por propia voluntad sin presión alguna y para declarar en un sentido muy concreto ${ }^{53}$.

Alonso de Monroy estuvo presente mientras se realizó la probanza en Almoharín. Al margen de las promesas realizadas a algunos testigos, intentó convencer a vecinos y testigos del lugar de que les interesaba que él ganase el pleito sobre este

\footnotetext{
${ }^{50}$ AChG, c. 14443, no 11, cuad. 3, fols. 56r-v.

${ }^{51}$ Miguel Hernández, vecino de Miajadas, señala que Juan Díaz de Valera le informó como "honbre amedrantado y que no sabia que se haria" lo que explica por ser Alonso de Monroy "honbre poderoso" (AChG, c. 14443, $\mathrm{n}^{\circ}$ 11 , cuad. 3 , fol. 28r).

${ }^{52}$ AChG, c. 14443 , no 11 , cuad. 3, fols. 55r-v.

${ }^{53}$ AChG, c. 14443, no 11, cuad. 3, fol. 46r.
} 
espacio de tanto interés para esta aldea por el aprovechamiento que habían realizado tradicionalmente ${ }^{54}$. Alonso de Monroy utiliza diversas tácticas con los testigos, al igual que con Juan Díaz de Valera. La amenaza parece ausente, pero intervienen el dinero u otras recompensas, incluida la posible disponibilidad de tierras en el espacio disputado. Alonso de Monroy siempre aparece como un personaje con un importante poder social y económico. De otro modo, no hubiera podido actuar de la forma indicada.

\section{CONCLUSIONES}

La información suministrada nos muestra de forma muy verosímil un intento sistemático de mediatización de la justicia con el fin de apropiarse de un amplio espacio con un importante valor económico. Hay varios aspectos sobre los que parece necesario reflexionar. El poder económico y político, particularmente el jurisdiccional, en el ámbito local/comarcal parecen herramientas fundamentales para cualquier intento de mediatización de la justicia. No estamos ante un desafío al poder real, algo ya pasado ${ }^{55}$, sino de intentos de aprovechar el poder para amañar probanzas e impedir o dificultar las ajenas como medio de obtener los derechos o bienes en juego. Intereses económicos, vínculos sociales, compra o parcialidad de los testigos y amenazas se juntan para generar miedo y temor, el suficiente como para que algunos deseen abandonar la escena aunque sin ceder a las peticiones realizadas.

En el caso que estudiamos, creemos ver dos protagonistas aunque uno sólo por omisión. Alonso de Monroy y su padre, disponen de una clara influencia en la tierra de Medellín, siempre condicionada, sustentada en bases económicas y sociopolíticas. Es sintomático de lo que decimos la actuación del cura de Escurial, que no desmerece de la de otros criados de la familia, o el interés que adivinamos en muchos vecinos de Almoharín de seguir accediendo en buenas condiciones a las tierras del colmenar en disputa. Es sorprendente la total ausencia del conde en este proceso. Todo nos

\footnotetext{
${ }^{54}$ Durante la probanza realizada en Almoharín, Juan Vaquero oyó decir "hablando el dicho don Alonso con los dichos vezinos del dicho lugar e con los testigos que declaravan que mas provecho les seria a los dichos vezinos y testigos quel saliese con el pleyto", porque podía "dar tierras a los dichos vecinos e testigos, e que pare ellos hera el provecho quel no lo avia menester” (AChG, c. 14443, n' 11, cuad. 3, fols. 46v-47r)

${ }^{55}$ En este sentido, es llamativo que en el pleito sobre la dehesa de Castilrubio que se desarrolla en 1570, poco antes del que nos ocupa, se hable por diversos testigos en contraste con este momento de "el tiempo de los robos e alteraçiones", referido al periodo que transcurre entre el comienzo de la crisis del poder real con Enrique IV y el sometimiendo de Beatriz Pachecho, condesa de Medellín, a la autoridad regia (Clemente Ramos, 2019: 144). En el mismo sentido, se documentan en el periodo bajomedieval intentos de impedir el acceso a la justicia real por diversos señores jurisdiccionales o de situarse al margen del poder real: Bermejo Cabrero, 1975: 211-2; Guilarte, 1987: 211; Pretel Marín, 1982: 293, n. 15.
} 
hace pensar que la actuación de Alonso de Monroy no sería viable sin la aquiescencia o la pasividad condal, explicable por una buena relación sancionada por un matrimonio y facilitada por el "exilio" de su padre Francisco de Monroy. Sin este último factor, todo el entramado se cae. No parece creíble que, avanzado el siglo XVI, se pueda actuar simultáneamente en contra de la justicia real y del conde, ni siquiera siendo un miembro cualificado de la oligarquía local.

Frente a este claro ataque a la legalidad, la respuesta social y el resultado final nos permiten visualizar la consolidación del poder real, y con ello de su justicia. En el último tercio del siglo XVI, el poder real está claramente asentado en la esfera local y ningún desafío es posible. Las amenazas infunden temor pero no se materializan en una violencia efectiva, sin duda ante el temor a la actuación de la justicia. El escribano elegido por Medellín, pese a las amenazas de Alonso de Monroy, realiza la correspondiente probanza y posteriormente declarará sobre sus actuaciones irregulares. Alonso de Monroy se ha encontrado con una respuesta efectiva de la justicia real, algo que sería impensable sin que los protagonistas la respeten y a su vez teman su ejecución. Se desarrolló una investigación sobre las actuaciones de Alonso de Monroy, aunque desgraciadamente no conocemos su resultado. Tampoco debemos esperar que la justicia real sea dura con los fuertes. El estado moderno se sustenta sobre un orden social preciso. Pero sin duda la victoria de los Reyes Católicos supuso la imposición de una legalidad y una justicia a las que, sin ser igualitarias, todos deben someterse.

\section{BIBLIOGRAFÍA}

BONNASSIE, P. (1988) Cataluña mil años atras (Siglos X-XI), Barcelona.

CABRERA MUÑOZ, E.: (1977): El condado de Belalcázar (1444-1518). Aportacion al estudio del regimen señorial en la baja Edad Media, Córdoba.

CASTELLANO GUTIÉRREZ, A.: (1987): “Aportación al estudio de los jurados del concejo de Jaén en la Baja Edad Media”, En la España Medieval, 10, pp. 249-262

CLEMENTE RAMOS, J.: (2006): "Martín Sancho (siglos XIV-XVI). Un despoblado bajomedieval en la tierra de Medellín.”, Hispania. Revista Española de Historia, 66/223 pp. 483-500.

(2007): La tierra de Medellín (1234-c. 1450). Dehesas, ganadería y oligarquía. Badajoz.

(2014): “La ganadería en Medellín (1450-1550): propietarios y cabañas", Anuario de Estudios Medievales, 44/2, pp. 807-844.

(2019) "Una dehesa por dentro: Castilrubio (1290-c. 1545). Paisaje, explotación y usurpación de términos", Espacio, Tiempo y Forma. III. Historia Medieval, 32, pp. 173-198 
BERMEJO CABRERO, J. L.: (1975): "Mayoría de la Justicia del Rey y jurisdicciones señoriales en la Baja Edad Media castellana”, Actas de las I Jornadas de Metodología Aplicada de las Ciencias Históricas, vol. 2, pp. 207-216.

FRANCO SILVA, A. y DEL PINO, J. L.: (1987): “El señorio de los Monroy (siglos XIIIXV)", Actas del Congreso Hernán Cortés y su tiempo, Mérida, 1987, pp. 156-7.

GERBET, M ${ }^{\mathrm{a}}$ Cl.: (1979): La noblesse dans le royaume de Castille. Étude sur ses structures sociales en Estrémadure (1454-1516), París.

GÓMEZ GONZÁLEZ, I.: (2017): "El control de la corrupción en los tribunales castellanos durante siglo XVII: ¿quimera o realidad?”, Tiempos Modernos. Revista Electrónica de Historia Moderna, 8/35, pp. 312-336.

GUILARTE, A. Ma: (1987): El régimen señorial en el siglo XVI, Valladolid, $2^{\mathrm{a}}$ edic.

HERNÁNDEZ RUANO, Javier: (2008): "Ensanchar la frontera jurisdiccional: Felipe II, los tribunales de justicia y el señorio de la orden de Montesa”, Europa: historia, imagen y mito. I Congreso Internacional, Castellón, pp. 335-354

KAGAN, R. L.: (1991): Pleitos y pleiteantes en Castilla, 1500-1700, Valladolid.

LORENZANA DE LA PUENTE, F.: (2003): “Jueces y pleitos: la administración de la justicia en la baja Extremadura en el Antiguo Régimen”, Hispania: Revista española de historia, 63/213, pp. 29-74.

PÉREZ, J.: (1998): “El Estado moderno y la Corrupción”, Instituciones y corrupción en la historia, Valladolid, 1998, pp. 111-129.

PRETEL MARÍN, A.: (1982): “Aproximación al estudio de la sociedad en La Mancha albacetense en el señorío de don Juan Manuel”, Don Juan Manuel: VII Centenario, Murcia.

QUINTANILLA RASO, María Concepción: (2003): "Vertebración del poder y la lógica señorial: la justicia en los estados nobiliarios de la baja Edad Media castellana", Os reinos ibéricos na Idade Média: livro de homenagem ao professor doutor Humberto Carlos Baquero Moreno, vol. 1, pp. 971-982

ROLDÁN VERDEJO, R.: (1989): Los jueces de la monarquía absoluta. Su estatuto y actividad judicial. Corona de Castilla, siglos XIV-XVIII, Santa Cruz de Tenerife, 1989.

Julián CLEMENTE

http://orcid.org/0000-0001-8900-9754

clemente@unex.es 
